\title{
Trabalhonecessário
}

Issn: 1808 - 799X

ano 13, número $20-2015$

\section{POLITECNIA, ESCOLA UNITÁRIA E TRABALHO: LIÇÕES DO PASSADO E DO PRESENTE}

Lucília Machado ${ }^{1}$

\section{Resumo}

O artigo situa a obra Politecnia, Escola Unitária e Trabalho no percurso intelectual da autora; apresenta alguns dos desafios encontrados para realizá-la e questões que a levaram ao prosseguimento das investigações sobre esses conceitos. Trata-se de um transcurso longo, de mais de 30 anos, que requereu a seleção de alguns temas pela sua recorrência ou permanência como questões que não estão ainda resolvidas ou que permanecem por decidir. $O$ artigo traz as principais referências bibliográficas das interlocuções estabelecidas para a produção da referida obra e discussão posterior. Ele apresenta também algumas das questões que carecem de investigações mais aprofundadas, tais como descrições sobre práticas pedagógicas que materializem a Pedagogia do Trabalho; esclarecimentos sobre diferenças entre a Pedagogia do Trabalho e as chamadas pedagogias ativas com relação à aplicação do princípio educativo da atividade; e se, como e porque o fetichismo tecnicista não se faz presente na Pedagogia do Trabalho.

Palavras-chave: Politecnia. Escola Unitária. Princípio educativo do trabalho.

1 Doutora em Educação (PUC-SP), Pós-doutora em Sociologia do Trabalho (Iresco-Paris), Professora titular aposentada da UFMG, coordenadora do Programa de Pós-graduação em Gestão Social, Educação e Desenvolvimento Local do Centro Universitário UNA (Belo Horizonte, MG). E-mail: Ismachado@uai.com.br. 


\section{Trabalhonecessário}

Issn: 1808 - 799X

ano 13, número $20-2015$

\section{Abstract}

The article situates the work Politecnia, Unitary School and Work in the intellectual journey of the author; presents some of the challenges encountered to perform it and issues that led to the continuation of investigations into these concepts. It is a long course of more than 30 years, which required the selection of some questions for its recurrence or stay as issues that are not resolved or that remain to be decided. The article presents the main references of dialogues established for the production of that work and further discussion. It also features some of the issues that need further investigation, such as descriptions of pedagogical practices that materialize the Pedagogy of Work; clarifications of differences between the Pedagogy of Work and the calls active pedagogies regarding the application of the educational principle of the activity; and if, how and why the technicalities fetishism is not present in the Pedagogy of Work.

Keywords: Politecnia. Unitary School. Educational principle of work.

\section{Introdução}

O livro Politecnia, Escola Unitária e Trabalho (MACHADO, 1989a) trouxe a público a tese de doutorado da autora, intitulada Unificação escolar e hegemonia, defendida em 1984, sob a orientação do Prof. Dr. Carlos Roberto Jamil Cury, no Programa de Doutorado em Educação da Pontifícia Universidade Católica de São Paulo, coordenado, à época, pelo Prof. Dr. Dermeval Saviani, que prefaciou a obra, resumindo bem sua estrutura:

Partindo das consequências escolares do processo de diferenciação social impulsionado pelo desenvolvimento capitalista (Cap. 1), a autora aborda as propostas liberal (Cap. 2) e socialista (Cap. 3 e 4) de unificação escolar, mostra as características específicas que o problema assumiu em diferentes formações 


\section{Trabalhonecessário}

Issn: 1808 - 799X

ano 13, número $20-2015$

sociais do Modo de Produção Capitalista (Cap. 5) e expõe as perspectivas divergentes no seio da luta dos trabalhadores pela escola unitária (Cap. 6). (SAVIANI, 1989 in MACHADO, 1989, p.7).

O problema que levou à definição da questão central dessa tese emergiu em pesquisa anterior para fins de conclusão de mestrado no âmbito do Programa em Educação da Universidade Federal de Minas Gerais, a transformação da escola a partir da "reunificação do que se encontra hoje dividido: a educação e a produção, o trabalho e a cultura" (MACHADO, 1989b, p. 148) e do "reordenamento do modo de se fazer ciência e de se empregar a técnica, como consequência da própria reunificação do trabalho intelectual e manual” (p. 149). A dissertação, também orientada pelo Prof. Dr. Carlos Roberto Jamil Cury, foi concluída em 1979 e publicada em livro em 1982, que recebeu o título Educação e Divisão Social do Trabalho.

Os Intelectuais e a Organização da Cultura (1968), obra seminal de Antonio Gramsci, foi uma das referências obrigatórias da dissertação. Autores como Braverman (1977), Gorz (1976), Lefebvre (1973) e Snyders (1977) também foram fundamentais para a realização da investigação. Na tese de doutorado, Marx (1973, 19--), Marx e Engels (1974, 1978, 1984) e Gramsci (1968, 1978, 1980, 1981) ganharam maior presença. A interlocução com Braverman (1977) foi mantida e outras obras Snyders $(1974,1977,1982)$ foram conhecidas. Foram incorporados outros autores, especialmente para o aprofundamento da reflexão sobre escola unitária, politecnica e o trabalho como princípio educativo. Dentre eles: Chauvelon (1972), Cogniot (1967), Dietrich (1976), Fitzpatrick (1977), Formizzi (1973), Fridman (1935), Fullat (1972), Hoernle (1934, 1972), Krupskaia (s/d, 1972), Lagardelle (1972, 1978), Lênin (1973, 1974, 1975), Levitas (1979), Sánchez Vázquez (1968) e Suchodolski (1974, 1976, 1978).

Com este artigo, busca-se situar a obra Politecnia, Escola Unitária e Trabalho no percurso intelectual da autora, o que ela lhe trouxe como desafios para sua realização e para o prosseguimento de suas investigações. Trata-se de 


\section{Trabalhonecessário}

Issn: 1808 - 799X

ano 13, número $20-2015$

um transcurso longo, de mais de 30 anos, o que requer uma seleção de alguns temas pela sua recorrência ou permanência como questão que não está ainda resolvida ou que permanece por decidir.

\section{A pesquisa realizada no doutorado}

O objetivo geral da pesquisa realizada consistiu em analisar a natureza das soluções apresentadas pelos campos do liberalismo e do socialismo para questões que envolvem o processo aparentemente concorrente, porém associado, de unificação e diferenciação escolar e suas relações com a divisão social do trabalho.

Tomou-se como recorte histórico o final do século dezenove, quando a escola passou a ganhar consideração e destaque no cenário das instituições de importância para o desenvolvimento das forças produtivas do capitalismo em razão do aumento da complexidade dos sistemas técnicos, dos processos de produção e da estrutura ocupacional. Ela passou também a ser reputada como instância fundamental para a formação do cidadão com relação ao cumprimento das regras da ordem social e estatal. A abordagem desse processo histórico se estendeu, nessa pesquisa, até a década de 40, quando se firmaram em quase todos os países princípios de estruturação dos sistemas nacionais de ensino.

A investigação se debruçou sobre a proposta liberal de escola única/unificada e simultaneamente diferenciada, que veio responder, de um lado, à necessidade de acomodação dessa instituição à direção da burguesia, sob o lema da educação como direito de todos e dever do estado. De outro, com perspectiva diferenciadora, essa proposta entendeu que a escola se organizaria de forma segmentada e hierarquizada para realizar funções sociais de formação geral para uns e de formação profissional para outros, sob a justificativa de que tais divisões decorrem das diferenças naturais de aptidões pessoais. 


\section{Trabalhonecessário}

Issn: 1808 - 799X

ano 13, número $20-2015$

Analisou-se a construção social do conceito de unificação escolar do ponto de vista liberal, vindo esse a se materializar na criação dos modernos sistemas nacionais de ensino, atendendo à necessidade universalista do processo de produção capitalista de contar com ampla força de trabalho talhada ao seu modo e aos interesses de unidade nacional, tão cara à afirmação da hegemonia burguesa. Tal perspectiva agregadora não rejeitou, porém, a perspectiva de uma diferenciação interna à estrutura escolar, de currículos e métodos pedagógicos para atender as necessidades da divisão social do trabalho capitalista e suas necessidades técnicas e de controle político e ideológico. A escola, conclamada como direito de todos, também foi recrutada a legitimar a distribuição desigual, as hierarquizações ocupacionais e o exercício diferenciado da cidadania por meio da criação de segmentações conforme tipos, níveis e qualidade de ensino.

Foram analisadas as clivagens que a escola unificada liberal trouxe e expressas na lógica dual do ensino, nas cristalizações que dificultam a concretização de perspectivas de integração curricular, nas desigualdades no tratamento à remuneração e carreira de docentes, nas falsas polarizações (teoria $\mathrm{x}$ prática, humanismo $\mathrm{x}$ ciência, tecnologia $\mathrm{x}$ ciência, educação científica $\mathrm{x}$ educação política), na apartação da sociedade civil da gestão escolar, nas desmobilizações e obstruções ostensivas ou dissimuladas à participação social nos assuntos educacionais pela via da subordinação ou cooptação em favor do projeto escolar unificador dominante. A despeito da prédica do direito de todos à educação, a escola unificada diferenciada tem servido à monopolização de privilégios de classe, aos novos corporativismos, às segregações justificadas por pretensas diferenças individuais quanto a aptidões, capacidades, interesses, vontades etc.

A pesquisa explorou o confronto feito por três correntes com a perspectiva liberal de unificação escolar: a socialista de viés reformista, o anarquismo e a marxista. Mostrou que o reformismo se caracterizou, historicamente, pela abdicação de um projeto de efetiva transformação social, pela subestimação da 


\section{Trabalhonecessário}

Issn: $1808-799 X$

ano 13, número $20-2015$

importância do fator subjetivo para a realização de inovações sociais, pela primazia às reivindicações econômicas, pelo apoio às teses liberais, entendendo que os compromissos em torno das reformas graduais das estruturas democrático burguesas seriam o caminho mais adequado à chegada ao socialismo.

A análise do que propunha a corrente anarquista evidenciou sua posição contra a igreja, o estado e as políticas educacionais de caráter geral, sua rejeição da herança cultural do capitalismo e do acesso à escola estatal por ela interpretado como suborno do proletariado pela burguesia. Propunha a fé na espontaneidade popular como elemento autônomo e regulador do desenvolvimento das autoconsciências e da autoeducação; a defesa da escola laica, autônoma e de classe; o fomento em separado da ciência proletária; a total liberdade das comunidades naturais e dos sindicatos de organização de escolas como forma de impedir a deformação ideológica que seria praticada pelas instituições do estado e da burguesia.

O estudo abordou também os elementos que constituíram a corrente marxista, que se pautou pelo pressuposto de não existir no capitalismo condição para que a escola seja a mesma para todos, já que a unificação escolar somente se efetivaria com a superação, na passagem do socialismo ao comunismo, dos fatores que levam às desigualdades sociais e às diferenciações escolares, essas associadas à lógica de funcionamento das sociedades de classes. Esse pressuposto traz a implicação da resolução prática das contradições capitalistas, especialmente as que se estabelecem entre necessidade e liberdade, indivíduo e espécie, objetivação e autoafirmação, naturalismo e humanismo, existência e essência. Segundo essa perspectiva, o capitalismo traria no seu próprio desenvolvimento as condições para a superação dessas contradições, mas isso não ocorreria de forma espontânea. Tal possibilidade se materializaria mediante intervenções concretas de todos, que sob a condução do proletariado com ampla base de apoio, intentassem nesse sentido. A ultrapassagem do capitalismo e de sua escola unificada diferenciada não se faria sem passar por esse sistema social 


\section{Trabalhonecessário}

Issn: $1808-799 X$

ano 13, número $20-2015$

e exigiria uma série de mediações, que incluiriam as conquistas parciais, a luta por direitos, as condições objetivas de aceleração desse processo mediante o desenvolvimento das forças produtivas, as condições subjetivas para as quais a educação jogaria importante papel. Essas mediações, submetidas à lógica da dialética entre continuidade e ruptura, não significariam o fim último da luta empreendida, crença no milagre democrático ou fortalecimento do poder burguês, mas ao pressionar o estado na direção das transformações necessárias o colocaria a serviço delas. A pesquisa realizada buscou analisar como a corrente marxista concebe a construção da práxis social pelas mediações entre objetividade e subjetividade, teoria e prática, reforma e revolução, espontaneísmo e direção, autonomia e interdependência, forma e conteúdo.

Ao discutir a concepção de escola na perspectiva de promoção dos avanços históricos que são fundamentais ao ideário socialista, a pesquisa realizada discutiu os conceitos de escola unitária e de politecnia, ambos referenciados na noção do trabalho como princípio educativo, na necessidade de superação do paradigma educacional dual, na recuperação do caráter unitário do conhecimento e na educação omnilateral.

Algumas das questões trazidas pelo livro continuam na agenda dos debates educacionais atuais. Dentre elas, podem ser mencionadas: a) a crítica às escolas e à educação profissional, que se apresentam com finalidades e interesses práticos imediatos e com funções meramente instrumentais; b) o acesso limitado e regrado dos trabalhadores à educação e as exigências capitalistas de controle e esvaziamento estratégico dessa educação; c) a importância da relação da escola com o trabalho, mas não com o trabalho que entorpece as capacidades humanas; d) a importância da relação da escola com o trabalho, mas não como uma questão puramente técnica; e) a subordinação da estrutura escolar, do processo pedagógico e da gestão educacional à lógica empresarial capitalista; f) a determinação das pedagogias diferenciadas e diferenciadoras pela divisão social do trabalho e pela organização capitalista do 


\section{Trabalhonecessário}

Issn: 1808 - 799X

ano 13, número $20-2015$

processo de trabalho; g) a crítica à regulação da cidadania pela hierarquização ocupacional; h) a polarização e correlação entre trabalho complexo e trabalho simples e entre formação geral e formação específica no contexto do desenvolvimento das forças produtivas e das mudanças na organização do trabalho; i) a importância do estreitamento das relações entre escola/educação e o contexto social; j) a necessidade de superação do ensino abstrato e formalista, da desvinculação entre as representações (dos objetos, fenômenos e processos) e os acontecimentos (da natureza e da vida social); k) a relação trabalho e educação na perspectiva da omnilateralidade, da escola unitária e da politecnia.

O doutoramento permitiu avançar na reflexão da questão que emergiu da dissertação de mestrado, porém trouxe lições e novos desafios. Os ensinamentos foram diversos. Cabe destacar alguns deles, que se mostraram mais significativos. O primeiro se refere à escolha do tema e problema da pesquisa, uma questão em geral inquietante para doutorandos, pois é preciso responder se são relevantes científica e socialmente, se são aderentes à proposta do programa de pós-graduação no seio do qual se fará o estudo, se corresponde às condições de tempo e pessoais para sua realização etc. É preciso confessar que as escolhas do tema e do problema foram realizadas sabendo-se que possivelmente grande parte do público para o qual o trabalho se dirigia os ignorava ou não thes reconhecia importância. É necessário lembrar que a pesquisa, iniciada em 1980, foi concluída em 1984, e que ainda vigia o regime ditatorial civil militar. Por conta dos anseios de liberdade e democracia era preciso pensar em projetos alternativos para a sociedade brasileira e, certamente, para a educação no país. Portanto, a escolha do tema e do problema da pesquisa carregava um sentido de urgência e compromisso político, de articulação da educação com os interesses da transformação social. A tese saiu publicada em livro em 1989, momento que veio evidenciar o acerto da decisão tomada com relação ao tema e problema da pesquisa. Assim se pronunciou Saviani no prefácio que fez para o livro: 


\section{Trabalhonecessário}

Issn: 1808 - 799X

ano 13, número $20-2015$

O último capítulo é particularmente atual no quadro de recomposição das forças políticas representadas pelo novo espectro partidário que se desenhou em nosso país. Com efeito, na medida em que a opção social-democrata se constitui como partido organizado, os partidos de esquerda assumem feição mais nítida embora ainda marcados por diferenças de análise, interpretação e formulação de estratégias e táticas de luta pela construção de uma nova sociedade. Nesse âmbito a contribuição teórica que Lucília nos traz no capítulo 6 ilumina de forma substantiva boa parte das polêmicas que têm sido travadas em nosso meio. Isto porque tais polêmicas trazem de modo geral a marca das tendências autonomista (anarco-sindicalista), reformista (social-democrata) e marxista (histórico-crítica) que são as três perspectivas que constituem o conteúdo central do último capítulo deste volume.

O momento da publicação do livro coincide com a conclusão da Constituição de 1988 e a emergência do ciclo dos trabalhos de concepção da nova Lei de Diretrizes e Bases da Educação Nacional, o que trouxe à tona propostas diversas de reformas educacionais. Os conceitos de escola unitária, politecnia e de trabalho como princípio educativo vieram alimentar os debates que se seguiram.

Aprendeu-se, assim, dar valor a percepções da relevância científica e social de questões para estudo quando apenas existem indícios delas na realidade. Aprenderam-se também os limites da pesquisa científica e dos conhecimentos por ela produzidos para a produção de mudanças nessa realidade. Atualmente o conhecimento histórico e teórico sobre os temas do trabalho como princípio educativo, da escola unitária e da politecnia já está mais alargado e disseminado. Não tanto quanto seria preciso. Porém, o que mais salta aos olhos é o quanto ainda não se avançou no debate sobre a necessidade de um sistema educacional unitário e coerente, que abranja o conjunto do país.

É importante destacar também que há bons aprendizados quando se assume o risco de escolher temas e problemas de pesquisa que oferecem certo grau de complexidade, quando a disponibilidade de bibliografias e documentos não é tão generosa, quando se faz necessário superar dificuldades para ler textos 


\section{Trabalhonecessário}

Issn: 1808 - 799X

ano 13, número $20-2015$

em diferentes idiomas, quando estudos prévios sobre o assunto são praticamente inexistentes no país e quando a alternativa que resta é a de amealhar informações esparsas para adensar a análise que se dispôs a fazer. Em face desse quadro de desafios, a lição representada pelo alerta do Prof. Cury, na sua função de orientador, foi muito importante: ou a investigação teria seu final frustrado ou o resultado obtido demarcaria o reconhecimento do seu caráter inédito. A confiança do orientador, Prof. Cury, do Prof. Saviani e dos colegas do doutorado de que era preciso ir à frente foi decisiva para reconhecer que uma tese de doutorado se faz também com o encorajamento de companheiros de viagem, ainda que essa seja solitária no fundamental.

Por fim, cabe destacar a importância das interlocuções durante a defesa de uma tese para a continuidade dos aprendizados. A Profa. Miriam Jorge Warde fez algumas perguntas que foram recebidas como uma intimação à continuidade das investigações sobre o tema. Ela indagou sobre onde teria prosperado o ideário socialista do trabalho como princípio educativo, da escola unitária e da politecnia. Perguntou quem promoveu e o realizou e sobre o como isso foi feito. Tais questões não foram discutidas na tese realizada já que elas não foram colocadas como problema para estudo naquele momento. Todavia, elas foram um incentivo para os estudos que se seguiram.

\section{A pesquisa Socialismo, Trabalho e Educação: o trabalho como princípio educativo em Cuba}

Entre 1988 e 1990, foi realizada essa pesquisa, por meio da qual se buscou investigar como Cuba realizava a inserção da educação na prática social tomando o trabalho como princípio educativo e mediação para a educação omnilateral e politécnica. Foram analisadas as contradições, emanadas do desenvolvimento educacional e da base técnico-material do país, que 


\section{Trabalhonecessário}

Issn: 1808 - 799X

ano 13, número $20-2015$

condicionavam a realização desse propósito e discutidas as perspectivas, que se apresentavam, de superação dessas contradições, notadamente, pela via políticopedagógica. Essa pesquisa contou com o apoio financeiro do CNPq, Capes e Fapemig. Foram feitas duas viagens a esse país e uma coleta de dados durante quatro meses. (MACHADO, 1988).

A pesquisa em Cuba permitiu avançar na compreensão do caráter mutuamente inclusivo que há entre revolução e educação, da função educativa como de responsabilidade de toda a sociedade, do trabalho como princípio educativo numa perspectiva ampliada, que envolve a mobilização e a integração de todos os esforços educativos de uma ampla rede de organizações, além das próprias escolas, pois requer a união do processo educativo com a vida e as práticas sociais. Possibilitou entender o quanto a necessidade de fazer corresponder a planificação do sistema nacional de ensino com 0 desenvolvimento econômico-social do país conferia à escola funções educativas amplas. Forneceu aspectos diversos da vinculação entre trabalho e educação, a principal forma considerada pela educação cubana e aplicável a todos os níveis do sistema educacional, de fazer a inserção da escola na prática social. Ofereceu elementos para perceber como o princípio da politecnia orientava a formação científica dos estudantes.

Foram analisadas as regulamentações para a participação das crianças e jovens com idade inferior a trinta anos nos processos de produção como parte do processo educacional e os diversos significados atribuídos a essa participação, especialmente o pedagógico:

um poderoso instrumento para o desenvolvimento multilateral dos estudantes; de formação de uma consciência de produtor; de combate a preconceitos e ao intelectualismo; de despertar a iniciativa e a compreensão das necessidades do país; de fomentar o espírito criador e investigativo pelo contato com a realidade prática; de melhorar a compreensão das teorias e sua utilização. Era visto também como um mecanismo para elevar o nível geral da cultura da população pelas trocas entre estudantes e 


\section{Trabalhonecessário}

Issn: 1808 - 799X

ano 13, número $20-2015$

trabalhadores; para favorecer a adoção de uma posição ativa perante a vida e estimular o aprendizado dos deveres sociais, da disciplina e da responsabilidade. Era, igualmente, entendido como um recurso que favorecia a harmonização das vontades individuais e coletivas; o fortalecimento da confiança, de cada um em si próprio, como resultado da necessidade de responder a desafios concretos; de construção, por todos, da percepção sobre a importância da própria vida para a sociedade em que se vivia. Era, enfim, visto como um meio de cultivar o valor e o respeito pelo trabalho humano; de fomentar a admiração recíproca entre estudantes e trabalhadores. (MACHADO, s/d)

Abordou-se também o propósito educativo dessa participação para a formação dos próprios professores, a politecnização da educação mediante a vinculação efetiva da produção da ciência com a produção material e a relação entre formação humana e novas relações sociais de produção. Questões curriculares e pedagógicas foram pesquisadas bem como as condições objetivas e subjetivas para a realização das finalidades do processo educacional. Foram exploradas, assim, as dimensões aplicadas do princípio da inserção da educação na prática social, contemplando os oito subsistemas educacionais (pré-escola, educação geral politécnica e laboral, educação técnica e profissional, formação e aperfeiçoamento do pessoal pedagógico, educação superior, educação de adultos, educação especial, educação extra-escolar).

A dialética das contradições inerentes à inserção da educação na prática social em Cuba mereceu destaque na pesquisa realizada. Tais contradições advinham do próprio desenvolvimento educacional e das limitações da base técnica e material da sociedade.

As primeiras estavam relacionadas à expansão do sistema educacional, às dificuldades de superar resquícios da pedagogia tradicional, às insuficiências da formação docente, às inadequações do processo pedagógico, às deficiências na organização do trabalho dos estudantes, à não-correspondência entre interesses da produção/serviços e os da docência, ao insuficiente intercâmbio entre centros de investigação e escolas. 


\section{Trabalhonecessário}

Issn: 1808 - 799X

ano 13, número $20-2015$

As contradições provenientes da base técnica e material decorriam das dificuldades para consolidar as novas relações de produção e de três ordens de necessidades: a) de elevar e satisfazer as necessidades básicas de todos, b) de investir no desenvolvimento das forças produtivas e definir o fator dinâmico da acumulação, e c) de aperfeiçoar o sistema de direção e planificação da economia.

Por fim, a investigação em Cuba procurou, no debate político-pedagógico ali em desenvolvimento, identificar propostas pautadas na relação trabalhoeducação que tivessem o sentido da busca da superação dessas contradições. Uma delas dizia respeito à transformação do caráter do trabalho e à formação da consciência socialista mediante a criação das condições objetivas e subjetivas para que o trabalho seja efetivamente mediação para novas relações sociais, de liberação da força criadora do povo e do seu poder.

\section{As perguntas que não querem calar}

Por força da sua relevância social e desafios teóricos e práticos que apresentam, os temas da politecnia, escola unitária e trabalho não somente permaneceram constantes ao longo dos últimos trinta anos, mas cresceu o número de pesquisadores que sobre eles têm se debruçado. Por conta da intensificação dos debates político-pedagógicos sobre eles, muitas questões permanecem em aberto. Dentre elas, destacam as que reclamam por descrições a respeito de práticas pedagógicas que materializem a Pedagogia do Trabalho; as que pedem mais esclarecimentos sobre em que difere a aplicação do princípio educativo da atividade na Pedagogia do Trabalho comparativamente ao que estabelecem e praticam as chamadas pedagogias ativas; e as que perguntam se, como e porque a Pedagogia do Trabalho se faz imune do fetichismo tecnicista.

Como autora do livro Politecnia, Escola Unitária e Trabalho, tais questionamentos têm sempre o viço das primeiras incursões pessoais a esses 


\section{Trabalhonecessário}

Issn: 1808 - 799X

ano 13, número $20-2015$

temas. Colocam, porém, responsabilidades maiores em vista do caráter concreto das demandas e dos contextos em que têm aparecido essas perguntas. Eles dizem respeito às tentativas de colocação em prática o que dizem nossos discursos e à discussão sobre como: a) formar professores na perspectiva da relação trabalho-educação; b) na realidade prática, fazer jus ao conceito de ensino médio integrado; c) realizar a interdisciplinaridade e a aprendizagem contextualizada; d) suprir a falta ou fazer as adequações dos recursos pedagógicos; e) superar os desencontros entre o que os estudantes estudam e as necessidades sociais; f) fazer a ampliação da escola para além dos seus muros; g) aumentar o nível de cultura tecnológica dos trabalhadores; i) aumentar o intercâmbio (praticamente inexistente) entre centros de investigação e escolas; j) tratar o intercâmbio entre o mundo da escola e o mundo do trabalho; k) o trabalho pode efetivamente ser mediação para novas relações sociais e liberação da força criadora e do poder popular.

\section{Considerações finais}

No livro Politecnia, escola unitária e trabalho, Marx, Lênin, Krupskaia, Pinkevich, Makarenko, Blonsky, Pistrak, Hoernle e Gramsci foram os principais interlocutores na abordagem da pedagogia socialista. Os desafios teóricos e práticos que se sucederam a essa obra, obrigou a autora a estudos aprofundados das obras já citadas de Marx e nas de Lukács $(1978,1979,2012)$ para maior densidade de suas discussões sobre a categoria atividade e a atividade do trabalho; a atividade e a ontologia do ser social; a atividade humana como atividade prática sensível e sobre o significado do contato prático com os objetos do mundo circundante na formação humana, pois os conhecimentos não existem na cabeça dos homens fora de alguma atividade. 


\section{Trabalhonecessário}

Issn: 1808 - 799X

ano 13, número $20-2015$

A pesquisa em Cuba ofereceu a oportunidade para o conhecimento das obras de outros autores (Vigotsky, Leontiev, Baktin, Galperin, Talízina, Davídov, Elkonin) e exploração de suas contribuições para a reflexão sobre a Pedagogia do Trabalho e seus desafios de efetivação prática. De Vigotsky (1987, 1999, 2003), vieram aportes importantes sobre a relação entre desenvolvimento humano e o contexto histórico-cultural; a linguagem como instrumento simbólico da atividade humana; o conceito de zona de desenvolvimento proximal; o papel da mediação dos objetos na relação social. De Leontiev (1983), a teoria da atividade contemplando todo um sistema que possui estrutura, movimentos internos, desenvolvimento; os nexos entre atividade, consciência e personalidade; e as noções de significados sociais e sentidos pessoais. De Galperin (2013a, 2013b, 2013c, 2013d, 2013e, 2013f), as implicações para a prática pedagógica do preceito de que a atividade de aprendizagem precisa estar orientada ao mundo das coisas e não somente ao mundo das ideias; de que a formação das ações mentais pressupõe etapas, sendo a primeira a ação material; de que apenas compreender como tem que fazer não significa que houve aprendizagem da ação; de que o objetivo da aprendizagem só é alcançado se o aluno cumpre a ação.

Outras interlocuções que têm sido também muito importantes para alimentar as reflexões da autora sobre a Pedagogia do Trabalho, particularmente as oferecidas por Haudricourt com seu célebre artigo sobre A tecnologia, ciência humana (1964); as estimuladas por Mauss e suas reflexões sobre as técnicas do corpo (2003); as trazidas por Leroi-Gourhan com suas abordagens sobre o homem e a matéria, o meio e as técnicas, o gesto e a palavra $(1983,1984,1985 a$, 1985b, 2010); e, por fim, as de Simondon com sua instigante pesquisa sobre o modo de existência dos objetos técnicos (2007). 


\title{
Trabalhonecessário
}

\author{
Issn: 1808 - 799X \\ ano 13, número $20-2015$
}

\section{Referências}

BRAVERMAN, H. Trabalho e capital monopolista. Rio de Janeiro: Zahar Editores, 1977.

CHAUVELON, E. Un mythe réformiste: l'école unique. In : LINDEBERG, D. L'Internationale Communiste et l'école de classe. Paris, François Maspero, 1972.

COGNIOT, G. Prométhée s'empare du savoir ; La Révolution d'Octobre, la culture et l'école. Paris : Éditions Sociales, 1967.

DIETRICH, T. Pedagogía socialista. Salamanca: Ediciones Sigueme, 1976.

FITZPATRICK, S. Lunacharski y la organización soviética de la educación y las artes (1917-1921). Madri: Siglo Veintiuno, 1977.

FORMIZZI, G. La pedagogía de Karl Marx. Brescia: Officine Grafiche. La Scuola, 1973.

FRIDMAN, S. Problemas de pedagogia marxista. São Paulo: Ed. Nacional, 1935.

FULLAT, O. La educación soviética. Barcelona: Editorial Nova Terra, 1972.

GALPERIN, P. Y.. A formação das imagens sensoriais e dos conceitos. In: Revista AMAzônica, Ano 6, vol. XI, n. 2, jul./dez. 2013a, p. 416-433.

. Tipos de orientação e tipos de formação das ações e dos conceitos. In:

Revista AMAzônica, Ano 6, vol. XI, n. 2, jul./dez. 2013b, p. 434-439.

. A formação dos conceitos e das ações mentais. Revista AMAzônica, Ano 6, vol. XI, n. 2, jul./dez. 2013c, p. 440-450.

Acerca da linguagem interna. In: Revista AMAzônica, Ano 6, vol. XI, n. 2, jul./dez. 2013d, p. 451-461.

. A direção do processo de aprendizagem. In: Revista AMAzônica, Ano 6, vol. XI, n. 2, jul./dez. 2013e, p. 478-484.

. Acerca do problema da atenção. In: Revista AMAzônica, Ano 6, vol. XI, n. 2, jul./dez. 2013f, p. 485- 494.

GORZ, A. Técnica, técnicos e luta de classes. In: Divisão social do trabalho e modo de produção capitalista. Porto: Publicações Escorpião, 1976.

GRAMSCI, A. A revolução contra O Capital. In: COUTINHO, C. N. Gramsci. Porto Alegre: L \& PM, 1981.

Concepção dialética da história. Rio de Janeiro: Editora Civilização Brasileira, 1978.

- Maquiavel, a política e o Estado moderno. Rio de Janeiro: Editora Civilização Brasileira, 1980.

. Os intelectuais e a organização da cultura. Rio de Janeiro: Editora Civilização Brasileira, 1968.

HAUDRICOURT, A.-G. La technologie, science humaine. La pensée, Paris, $n$. 115, mai-juin 1964, p. 28-35.

HOERNLE, E. Educação burguesa e educação proletária. São Paulo: Editora Unitas, 1934. 


\section{Trabalhonecessário}

Issn: 1808 - 799X

ano 13, número $20-2015$

Réflexions de $\mathrm{K}$. Marx sur quelques problèmes fondamentaux de la politique scolaire prolétarienne. In: LINDENBERG, D. L'Internationale Communiste et l'école de classe. Paris, François Maspero, 1972.

KRUPSKAIA, N. Acerca de la educación comunista. Moscú: Ediciones en Lenguas Extranjeras, s/d.

Une école neutre est-elle possible? In: LINDENBERG, D. L'Internationale Communiste et l'école de classe. Paris, François Maspero, 1972.

LAGARDELLE, H. El monopolio de la enseñanza. In: MAYOL, A. (Ed.). Boletín de la "Escuela Moderna". Barcelona: Tusquets Editor, 1978.

L'école et le prolétariat. In: LINDENBERG, D. L'Internationale Communiste et l'école de classe. Paris, François Maspero, 1972.

LEFEBVRE, H. A re-produção das relações de produção. Porto: Publicações Escorpião, 1973.

LÊNIN, V. I. Marxismo e revisionismo. In: O que é o marxismo. Lisboa: Ed. Estampa, 1974.

. Materialismo e empiriocriticismo. Lisboa: Editorial Estampa, 1975.

Obras escogidas, 6 v.. Buenos Aires: Editorial Cartago, 1973.

Sobre a educação, v. 1 e 2. Lisboa: Seara Nova, 1977.

LEONTIEV, Alexis N. Actividad, conciencia, personalidad. La Habana: Editorial Pueblo y Educación, 1983.

LEROI-GOURHAN, A. Evolução e técnicas 1: o homem e a matéria. Lisboa: Edições 70, 1984. 252p.

360p.

Evolução e técnicas 2: o meio e as técnicas. Lisboa: Edições 70, 1985a.

1985b.

O gesto e a palavra. v. I - Técnica e Linguagem. Lisboa: Edições 70,

O gesto e a palavra. v. II - Memória e Ritmos. Lisboa: Edições 70, 1983.

A libertação da mão. Laboreal, v. VI, n. 2, 2010, pp. 56-59.

LEVITAS, M. Marxismo y sociología de la educación. México: Siglo Veintiuno Editores, 1979.

LUKÁCS, G. As bases ontológicas do pensamento e da atividade do homem. Temas de Ciências Humanas. São Paulo: Ciências Humanas, 1978.

. Ontologia do ser social: os princípios ontológicos fundamentais de Marx. São Paulo: Ciências Humanas, 1979.

. Por uma ontologia do ser social, I. São Paulo: Boitempo Editorial, 2012.

MACHADO, L. R. S. Educação em Cuba: revolução na revolução? Educação em Revista, Belo Horizonte, v. 7, n.7, p. 3-9, 1988.

. Politecnia, escola unitária e trabalho. São Paulo: Cortez Editora; Autores Associados, 1989a.

. Educação e divisão social do trabalho. 2a Ed. São Paulo: Autores Associados: Cortez, 1989b.

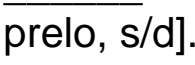

A inserção da educação na prática social: a experiência de Cuba. [no 


\title{
Trabalhonecessário
}

\author{
Issn: 1808 - 799X \\ ano 13, número $20-2015$
}

MARX, K. Crítica ao Programa de Gotha. In: MARX, K.; ENGELS, F. Obras Escolhidas, v. 2. S. Paulo, Ed. Alfa-Ômega, 19--. p. 233-234.

O Capital. Crítica de la economía política. México: Fondo de Cultura Económica, 1973. 1978.

; ENGELS, F. Crítica da educação e do ensino. Lisboa: Moraes editores, Grijalbo, 1974.

; ENGELS, F. La Ideologia Alemana. Montevideo; Barcelona: Pueblos; 1984.

; ENGELS, F. Manifesto do Partido Comunista. São Paulo: Global Editora,

MAUSS, Marcel. As técnicas do corpo. In: Sociologia e Antropologia. São

Paulo: Cosac e Naify, 2003, p. 399-422.

SÁNCHEZ VÁZQUEZ, A. Filosofia da práxis. Rio de Janeiro: Editora Paz e Terra, 1968.

SAVIANI, D. Prefácio. In: MACHADO, L. R. S. Politecnia, escola unitária e trabalho. São Paulo: Cortez Editora; Autores Associados, 1989, p. 7-8.

SIMONDON, Georges. El modo de existencia de los objetos técnicos. Buenos Aires, Prometeo Libros, 2007.

SNYDERS, G. Escola, classe e luta de classes. Lisboa: Moraes Editores, 1977. . La pedagogía progresista como esperanza. In: Cuadernos de Pedagogía, ano VIII, n. 88, abr. 1982.

. Pedagogia progressista. Coimbra: Livraria Almedina, 1974.

SUCHODOLSKI, B. Fundamentos de pedagogía socialista. Barcelona: Editorial Laia, 1974.

Teoria marxista da educação. Lisboa: Editorial Estampa, 1976.

1978.

. A pedagogia e as grandes correntes filosóficas. Lisboa: Livros Horizonte,

VYGOTSKY, L. Pensamento e Linguagem, SP: Martins Fontes, 1987.

. Formação Social da Mente, SP: Martins Fontes, 1999.

. Psicologia Pedagógica. Porto Alegre, Artmed, 2003.

Recebido em 02 de outubro de 2014 Aprovado em 08 de novembro de 2014 